\title{
PERANCANGAN VIDEO PROFILE PADA SMK ISLAMIC VILLAGE KARAWACI KABUPATEN TANGERANG
}

\author{
Lusyani Sunarya $^{1}$ \\ Hirzi Supriadi Saputra ${ }^{2}$ \\ Dwi Rahmadhiani ${ }^{3}$ \\ Dosen STMIK Raharja ${ }^{1}$ \\ STMIK Raharja Jurusan Teknik Informatika ${ }^{2,3}$ \\ Jl. Jenderal Sudirman No. 40 Modern Cikokol Tangerang ${ }^{1,2,3}$ \\ E-mail : $\underline{\text { lusyani@raharja.info }}{ }^{1}, \underline{\text { hirzi@raharja.info }}{ }^{2}, \underline{\text { dwi@raharja.info }}{ }^{3}$
}

\begin{abstract}
ABSTRAK
Dunia pendidikan memiliki perkembangan yang pesat, dilihat dari semakin banyaknya sekolah-sekolah yang mengembangkan promosi agar dapat lebih dikenal oleh masyarakat luas. Tujuan penelitian ini adalah merancang media audio visual dalam bentuk video profile agar dapat menjadi daya tarik yang efisien dalam penyampaian informasi dan promosi. SMK Islamic Village Karawaci Kabupaten Tangerang adalah lembaga pendidikan yang berbasis Islami dan terkenal dengan lulusannya yang berkualitas. Namun, sekolah tersebut belum mempunyai media informasi yang lengkap dan efektif tentang profil sekolah tersebut. Selama ini, sekolah hanya memanfaatkan media komunikasi visual, berupa brosur, spanduk, dan lainnya. Maka dari itu dibutuhkan sebuah Perancangan Video Profile pada SMK Islamic Village Karawaci Kabupaten Tangerang, sebagai media promosi serta informasi yang menjadi daya tarik siswa/i baru untuk bergabung di SMK Islamic Village. Dengan menggunakan metode pengumpulan data dan konsep produksi media yang meliputi : preproduction, production, dan postproduction, diharapkan dapat memberikan informasi dan promosi yang efektif dan efisien. Sehingga hasil akhir yang didapat dari penelitian ini yaitu terciptanya sebuah rancangan media penunjang informasi dan promosi berbentuk video profile yang efektif dan sesuai dengan kebutuhan serta mampu meningkatkan target pemasaran sekolah.
\end{abstract}

Kata kunci Informasi, Promosi, Video Profile.

\section{ABSTRACT}

The world of education has rapid development, seen from the increasing number of schools that develop promotions to be better known by the public. The purpose of this study is to design audio-visual media in the form of video profiles that can be an attraction that is efficient in the delivery of information and promotion. SMK Islamic Village Karawaci Tangerang regency is based educational institution famous for its Islamic and qualified graduates. However, the school does not have a complete media and effective information about the school's profile. During this time, the school only use visual communication media, such as brochures, banners, and more. Therefore it takes a Design Video Profile on vocational Islamic Village Karawaci Tangerang District, as well as information media campaign to attract students / $i$ new to join in vocational Islamic Village. By using the method of data collection and the concept of media production that include: preproduction, production and postproduction, is expected to provide the information and promotion of effective and efficient. So that the final results obtained from this research is the creation of a media plan supporting information and promotional videos shaped profile that is effective and in accordance with the needs and able to improve targeted marketing of the school.

Keywords : Information, Promotion, Video Profile. 


\section{PENDAHULUAN}

Teknologi adalah salah satu sarana guna menyampaikan informasi dalam hal memperkenalkan suatu produk atau jasa, salah satunya yaitu sebuah lembaga pendidikan. Dalam menyampaikan informasi yang efektif media yang tepat digunakan adalah audio visual, karena media audio visual dapat memenuhi kebutuhan dalam penyampaian informasi dan promosi yang menarik dan efektif untuk diberikan kepada audience. Informasi tersebut digunakan oleh suatu lembaga untuk mempromosikan ataupun menciptakan citra positif dari audience yang melihatnya.

Agar dapat meningkatkan pangsa pasar, suatu lembaga membutuhkan sarana penunjang informasi dan promosi, seperti membuat video profile yang saat ini banyak digunakan oleh lembaga atau instansi pendidikan sebagai wadah promosi. Biasanya, video profile itu berisi tentang penjelasan dan paparan mengenai seluruh ruang lingkup yang ada di sebuah lembaga pendidikan seperti profil sekolah, sejarah sekolah, akreditasi sekolah, keunggulan sekolah, prestasi sekolah, fasilitas yang dimiliki sekolah serta visi dan misi sekolah dalam dunia pendidikan.

SMK Islamic Village Karawaci Kabupaten Tangerang adalah salah satu sekolah menengah kejuruan yang berbasis islam di Indonesia. Sekolah yang beralamatkan di Jl. Islamic Raya, Kelapa Dua, Kabupaten Tangerang ini memiliki visi yaitu mewujudkan masyarakat yang tumbuh dan berkembang di atas nilai nilai ajaran Islam. Untuk mewujudkan visi atau harapan tersebut Yayasan Islamic Village menetapkan dua bidang garapan utama, yaitu sosial dan pendidikan. Di bidang sosial yayasan berusaha memberdayakan golongan masyarakat lemah, khususnya anak-anak yatim piatu, terlantar, dan tidak mampu dengan memberinya bekal pendidikan dan keterampilan yang layak. Sedangkan di bidang pendidikan, yayasan merencanakan program pembinaan terencana dan sistematis untuk menghasilkan generasi islam yang dapat diandalkan di masa yang akan datang.

Melalui perancangan media video profile ini, diharapkan kebutuhan informasi yang diinginkan masyarakat dapat terpenuhi dan menarik minat calon siswa/siswi baru untuk bersekolah di SMK Islamic Village Karawaci Kabupaten Tangerang, dikarenakan isi dari video profile ini mencakup secara detail tentang ruang lingkup sekolah meliputi visi dan misi, tujuan sekolah, kegiatan pembelajaran, keunggulan ataupun prestasi yang dimiliki sekolah SMK Islamic Village Karawaci Kabupaten Tangerang. Perancangan media video profile ini dapat menjadi sarana penunjang informasi dan promosi yang diberikan pihak pemasaran dalam berbagai kegiatan sekolah seperti presentasi penerimaan calon siswa/siswi baru, kegiatan workshop, pameran sekolah dan kegiatan sekolah lainnya. Banyak harapan yang diinginkan dari perancangan video profile ini seperti halnya peningkatan angka pendaftaran calon siswa/i baru untuk bergabung di SMK Islamic Village Karawaci Kabupaten Tangerang, serta meningkatkan citra sekolah agar semakin dikenal khalayak luas.

\section{RUMUSAN MASALAH}

SMK Islamic Village Karawaci Kabupaten Tangerang adalah salah satu sekolah menengah kejuruan yang berbasis islam di Indonesia. Saat ini SMK Islamic Village Karawaci Kabupaten Tangerang belum mempunyai media informasi yang lengkap, menarik, dan efektif tentang ruang lingkup sekolah meliputi : profil sekolah, fasilitas, kegiatan, dan keunggulan dari sekolah tersebut. Selama ini, sekolah hanya memanfaatkan media komunikasi visual, berupa brosur, spanduk, pamflet, dan lainnya. Maka dari itu dibutuhkanlah sebuah Perancangan video profile pada SMK Islamic Village Karawaci Kabupaten Tangerang, sebagai sarana penunjang promosi serta informasi untuk menarik audience khususnya calon siswa/siswi baru dan masyarakat untuk bergabung di sekolah SMK Islamic Village Karawaci Kabupaten Tangerang. Perancangan media video profile 
ini dapat menjadi sarana penunjang informasi dan promosi yang diberikan pihak pemasaran dalam berbagai kegiatan sekolah seperti presentasi penerimaan calon siswa/siswi baru, kegiatan workshop, pameran sekolah dan kegiatan sekolah lainnya. Selain itu melalui perancangan video profile ini, akan meningkatkan angka pendaftaran calon siswa/i baru untuk bergabung di SMK Islamic Village Karawaci Kabupaten Tangerang, serta meningkatkan citra sekolah agar semakin dikenal khalayak luas.

\section{LANDASAN TEORI}

\section{Pengertian Perancangan}

Menurut Kausar, dkk (2015:22), perancangan merupakan pengembangan sistem dari sistem yang sudah ada atau sistem yang baru, dimana masalah-masalah yang terjadi pada sistem lama diharapkan sudah teratasi pada sistem yang baru. Tahap perancangan sistem mempunyai dua tujuan utama, yaitu :

1. Untuk memenuhi kebutuhan kepada pemakai sistem

2. Untuk memberikan gambaran yang jelas dan rancangan desain yang lengkap kepada ahli-ahli teknis lainnya yang terlibat. ${ }^{[1]}$

\section{Konsep Dasar Media}

Menurut Maimunah, dkk (2012:284), Media adalah saluran penyampaian pesan komersial kepada khalayak sasaran atau dapat dikatakan salah satu komunikasi periklanan yang dilakukan melalui saluran media tertentu, seperti majalah, surat kabar, televisi, radio, internet, media luar ruang, buku profil, iklan transit dan direct mail. ${ }^{[6]}$

\section{Konsep Dasar Video Profile}

Menurut Saftanto (2013-243), Video profile merupakan salah satu media yang efektif dalam mempropagandakan perusahaan,produk, hingga propaganda untuk potensi daerah. Dengan komunikasi melalui audio visual tentunya penyampaian propaganda atau promosi semakin efektif. ${ }^{[8]}$

\section{Konsep Dasar Promosi}

Menurut Desrianti, dkk (2014:425), promosi adalah tindakan menginformasikan atau meningkatkan konsumen tentang spesifikasi merek atau produk. Promosi mempunyai kekuatan untuk menyampaikan pesan, dan diperlukan perancangan khusus agar promosi tersebut menciptakan keserasian didalam rangkaian pemasaran dan memiliki visual yang kuat, karena promosi adalah berkaitan langsung dalam usaha untuk memperkenalkan produk kepada konsumen dengan cara memikat hati mereka melalui pemberian kesan-kesan baik, yang mampu diingat dan dirasakan oleh konsumen. ${ }^{[3]}$

\section{Konsep Dasar Informasi}

Menurut Hutahaen (2014:9), informasi adalah data yang diolah menjadi bentuk yang lebih berguna dan lebih berarti bagi penerimanya. Sumber informasi adalah data. Data kenyataan yang menggambarkan salah satu kejadian-kejadian dan kesatuan nyata. Kejadian-kejadian (event) ialah kejadian yang terjadi pada saat tertentu. ${ }^{[5]}$

\section{Program Aplikasi Penunjang Video Profile}

\section{Adobe Premiere CS6}

Menurut Bentelu, dkk (2016 : 4), Adobe Premiere adalah salah satu software yang populer dan digunakan secara luas dalam pengeditan video. Ada antarmuka yang sama dengan Adobe Photoshop. Adobe Premiere dan Adobe After Effect adalah untuk memberikan kemudahan penggunaan, gambar - gambar dapat dibuat dengan Adobe Photoshop dan efek - efek khusus juga dapat disiapkan dari Adobe After Effect. Adobe Premiere merupakan program yang sudah umum digunakan oleh rumah - rumah produksi, televisi dan praktisi dibidangnya. Keuntungan belajar melakukan edit video menggunakan fungsi utama Adobe Premiere lebih untuk merangkai gambar, video, dan audio, bukan untuk animasi, agar penampilan multimedia lebih menarik. ${ }^{[2]}$ 


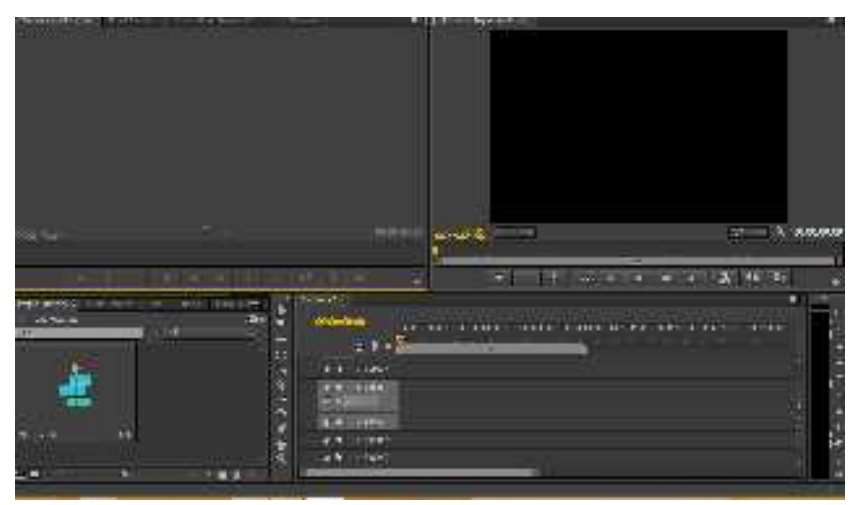

Gambar 1. Adobe Premiere CS6

\section{Adobe After Effect}

Menurut Waloeya, (2012 : 1), Adobe After Effect adalah software motion graphics yang digunakan sebagai software animasi, video effect, dan compositing. Adobe After Effect merupakan software animasi bukan untuk mengedit foto sehingga mengedit foto perlu menggunakan Photoshop. After Effect pun bukan software video editing, sehingga untuk merangkai video dengan durasi relative panjang harus menggunakan Adobe Premiere. After Effect pun bukan software animasi $3 D$, sehingga untuk membuat animasi $3 D$ lebih powerfull akan lebih baik jika menggunakan $3 D$ Studio $\operatorname{Max} .^{101}$

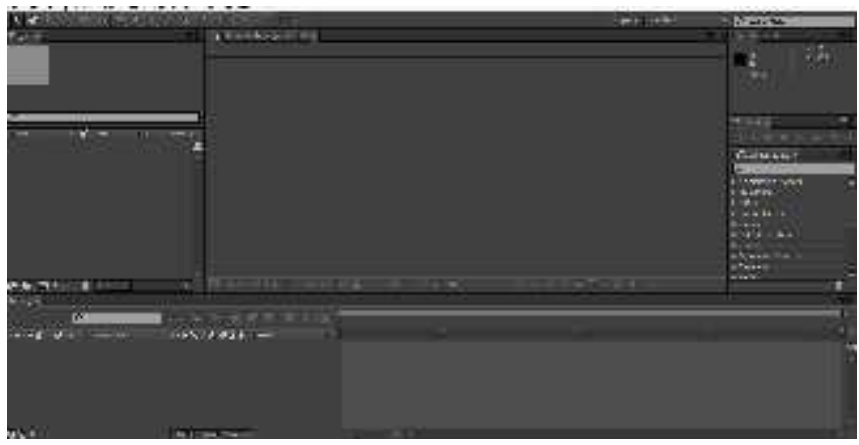

Gambar 2. Adobe After Effect CS6

\section{Adobe Photoshop CS6}

Madcoms (2012: 1 - 37), mengemukakan Adobe kembali merilis program Photoshop versi terbaru yaitu Photoshop CS6. Dalam versi terbarunya ini, Photoshop CS6 semakin menunjukkan kepiawaiannya sebagai program pengolah foto digital yang semakin professional. Selain itu, ada juga versi terbaru dari Photoshop $C C^{[7]}$

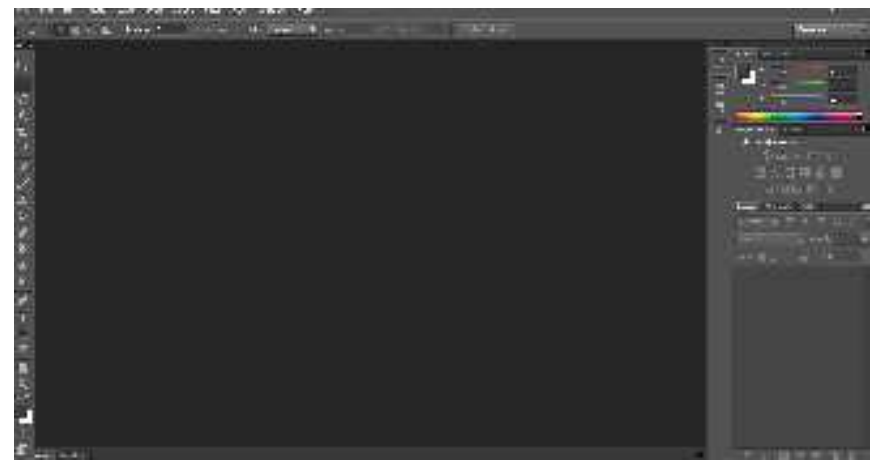

Gambar 3. Adobe Photoshop CS6 


\section{Pengacuan Pustaka}

Studi pustaka bertujuan untuk membandingkan tingkat keberhasilan dan memperkuat hasil yang telah dibuat, kemudian difungsikan sebagai landasan teori. Banyak artikel ilmiah tentang perancangan video profile, serta artikel ilmiah terkait lainnya yang juga dijadikan referensi, beberapa diantaranya adalah sebagai berikut :

1. Penelitian yang dilakukan oleh Septiana Firdaus, dkk tahun 2012 berjudul "Perancangan Aplikasi Multimedia Interaktif Company Profile Generic (Studi Kasus CV. Ganetic)". Penelitian ini berisi tentang perancangan multimedia interaktif company profile generic untuk menyampaian informasi secara visual dengan animasi yang menarik sehingga menambah daya tarik calon client untuk mempelajari tentang pengenalan sebuah perusahaan. Perancangan ini diharapkan menjadi sebuah pemecahan masalah untuk mengenalkan kepada dunia luar mengenai profil organisasi/perusahaan/instansi swasta/pemerintahan tentang pelayanan yang dilakukan, riset produk, produk yang telah dibuat maupun jasa yang telah diberikan dengan cara interaktif yang mudah diserap dan diingat mengenai profile tersebut. ${ }^{[4]}$

2. Penelitian yang dilakukan oleh Sutrisno di tahun 2015 berjudul "Pembuatan Video Profil Sekolah Dasar Negeri Menadi Kabupaten Pacitan Berbasis Multimedia". Penelitian ini membahas tentang bagaimana membuat video profil dengan menggunakan komputer multimedia. Dengan menggunakan komputer multimedia, diharapkan mampu menghasilkan video profil yang dapat menjadi media promosi dan informasi serta dokumentasi bagi Sekolah Dasar Negeri Menadi. ${ }^{[9]}$

3. Penelitian yang dilakukan oleh Ahmad Kausar, dkk tahun 2015 berjudul "Perancangan Video Company Profile Kota Serang Dengan Teknik Editing Menggunakan Adobe Premiere PRO CS 5". Penelitian ini membahas tentang teknik editing membuat video company profile dengan menggunakan software Adobe Premiere Pro CS 5. Dengan menggunakan software Adobe Premiere Pro CS 5 diharapkan mampu menghasilkan video profile yang maksimal sebagai sarana informasi. ${ }^{[1]}$

4. Penelitian yang dilakukan oleh Maimunah, dkk tahun 2012 berjudul "Media Company Profile sebagai Sarana Promosi dan Informasi". Penelitian ini membahas tentang bagaimana cara menunjang sarana informasi dan promosi melalui media company profile agar dapat memberikan informasi yang efektif dan menarik. ${ }^{[6]}$

5. Penelitian yang dilakukan oleh Saftanto, tahun 2013 berjudul "Pembuatan Video Company Profile Pada Sekolah Menengah Atas Muhammadiyah 1 Karanganyar". Penelitian ini membahas tentang Sekolah Menengah Atas Muhammadiyah Karanganyar dalam penyampaian informasi kepada masyarakat masih menggunakan cara-cara konvensional seperti penyebaran brosur-brosur, spanduk dan masih secara lisan sehingga kurang menarik dan kurang promotif. Diharapkan dengan pembuatan video profile ini masyarakat luas dapat dengan mudah mendapatkan informasi tentang Sekolah Menengah Atas Muhammadiyah Karanganyar. ${ }^{[8]}$

6. Penelitian yang dilakukan oleh Sunarya, dkk tahun 2017 berjudul "Perancangan Media Promosi Video Profile Pada SMA Negeri 15 Kota Tangerang". Penelitian ini membahas tentang penyampaian informasi dan promosi yang efektif dengan menggunakan audio visual khususnya kepada siswa/i dan untuk menjalin relasi dengan sekolah lain. ${ }^{[13]}$

7. Penelitian yang dilakukan oleh Budiman, dkk tahun 2016 berjudul "Perancangan Media Presentasi Company Profile Universitas Negeri Padang Berbasis Multimedia Interaktif". Penelitian ini membahas tentang guna menyempurnakan informasi dan promosi yang lebih menarik lagi, maka dibutuhkan media yang mampu memberikan informasi yang secara cepat dan akurat. Dengan menggunakan tampilan visual dapat memberikan tampilan yang lebih menarik dan efektif bagi Universitas Negeri Padang. ${ }^{[4]}$

8. Penelitian yang dilakukan oleh Mahmudi, tahun 2015 berjudul "Pembuatan Video Profile Sekolah Dasar Negeri Tlogo CV Bootsector". Penelitan ini membahas tentang media yang menarik sebagai sarana promosi sekolah Dasar Negeri Tlogo sehingga dapat lebih mengekspos tentang sekolah Dasar Negeri Tlogo yang memiliki banyak prestasi. ${ }^{[2]}$

9. Penelitian yang dilakukan oleh Astuti, tahun 2014 berjudul "Pembuatan Video Profil Sekolah Dasar Negeri 1 Tugu Jumantono Kabupaten Karanganyar". Penelitian ini membahas tentang pengunaan video profil sebagai suatu profil sekolah yang memerlukan sebagai sarana informasi dan promosi. ${ }^{[8]}$ 


\section{METODE PENELITIAN}

Agar melengkapi dan mendapatkan data-data yang dibutuhkan dalam penulisan berkaitan dengan perancangan video profile yang akan di buat ini, penulis menggunakan beberapa metode penelitian. Berikut metode penelitian yang di gunakan oleh penulis :

\section{Metode Pengumpulan Data}

1. Metode Observasi

Melakukan observasi langsung ke SMK Islamic Vilage Karawaci Kabupaten Tangerang untuk memperoleh data-data yang diperlukan dalam penelitian dengan melakukan survei secara langsung dan melakukan pencatatan secara sistematis.

2. Metode Wawancara

Melakukan wawancara atau tanya jawab secara langsung kepada pihak stakeholder yang bukan lain adalah kepala sekolah dan staff-staff SMK Islamic Village Karawaci Kabupaten Tangerang untuk mendapatkan informasi serta data-data yang dibutuhkan berkaitan dengan penelitian.

3. Metode Triangulasi

Melakukan pemeriksaan keabsahan data yang telah di dapat mengenai SMK Islamic Village agar data yang telah di dapatkan menjadi data yang sah dan dijamin kebenarannya sehingga tidak menimbulkan fiktif belaka dengan cara membandingkan data yang di dapat pada saat observasi dan wawancara dengan data yang sudah beredar di masyarakat.

4. Metode Studi Pustaka

Tidak hanya melakukan melakukan observasi langsung, wawancara, dan pemeriksaan kembali data, penelitian ini juga mempelajari buku-buku yang terkait topik penelitian dan mempelajari elemen-elemen objek yang sedang di teliti.

\section{Metode Konsep Produksi Media}

Konsep produksi media memiliki tahapan-tahapan dalam pelaksanaannya, yaitu :

1. Preproduction

2. Production

3. Postproduction

\section{PEMBAHASAN}

\section{Tahapan Konsep Produksi Media}

Konsep produksi Media adalah tahapan untuk mencapai efisiensi produk dengan menggunakan teknik Media yang merupakan singkatan dari Multimedia Audio Visual dan Broadcasting yang merupakan bidang ilmu design yaitu dua dimensi, tiga dimensi dan penggabungan dari dua dengan tiga dimensi. Kemajuan dari Media akan menghasilkan suatu media audio visual yang menarik untuk disajikan. Dengan Konsep Produksi Media tersebut media video yang dibuat akan menjadi lebih baik dalam segi produksi maupun teoritisnya. Langkah dari Konsep Produksi Media dimulai dari Preproduction lalu Production dan yang terakhir Postproduction.

\section{KPM}

PREPRODUCTION

PRODUCTION

POSTPRODUCTION

Gambar 4. Konsep Produksi Media 


\section{Preproduction}

Preproduction adalah langkah dimana dimulainya ide, perencanaan dan persiapan dari Konsep Produksi Media. Ada tujuh langkah Preproduction dalam Konsep Produksi Media, dimulai dari ide yang dituangkan secara sistematis, kemudian diikuti dengan pembuatan sinopsis, Script Writing dan Storyboard. Dua tahap terakhir adalah pemilihan pemain dan crew dan Setting Alat. Semua tahapan harus sesuai dengan Time Schedule yang ditetapkan. Untuk lebih jelasnya di ilustrasikan pada bagan berikut ini :

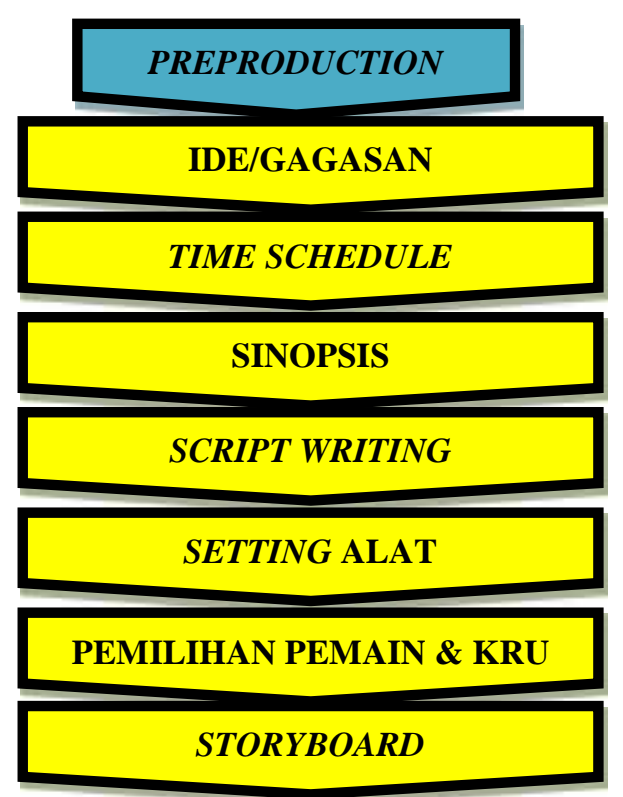

Gambar 5. Tahap Preproduction

\section{Ide/Gagasan}

Media informasi yang sering kita nikmati merupakan bentuk perwujudan dari sebuah ide pemikiran dan gagasan yang telah dituangkan kedalam media dalam hal ini media audio dan visual (video). Media informasi yang dibuat mengambil ide dari profile SMK Islamic Village Karawaci Kabupaten Tangerang, media informasi yang dibuat mengambil garis besar dari ide tersebut.

\section{Sinopsis}

Sinopsis adalah ringkasan dari sebuah cerita atau film, menjadi bentuk pemendekan dari sebuah feature documenter dengan tetap memperhatikan unsur yang ada pada feature documenter tersebut. Sinopsis dibatasi dari jumlah halamannya, misal setengah, satu atau dua halaman dari panjang feature documenter. Sinopsis perancangan video profile sebagai media promosi dan informasi pada SMK Islamic Village Karawaci Kabupaten Tangerang ini adalah :

SMK Islamic Village Kabupaten Tangerang adalah salah satu instansi bidang pendidikan berdiri pada tahun 1995 dengan nama Sekolah Menengah Ekonomi Atas (SMEA) Islamic Village dengan Kompetensi Kejuruan yang tersedia adalah Akuntansi. Setelah berjalan dua tahun, tepatnya tanggal 19 Juli 1997 mendapatkan izin operasional bagi Yayasan Islamic Village cabang Tangerang untuk membangun SMEA/SMK Islamic Village mulai tahun ajaran 1996/1997 yang merupakan instansi swasta bidang pendidikan yang beralamat di jalan Islamic Raya, Kelapa Dua, Kabupaten Tangerang, Propinsi Banten. SMK Islamic Village Karawaci Kabupaten Tangerang mendapat status terakreditasi A SMK Islamic Village Karawaci Kabupaten Tangerang dilengkapi dengan fasilitas ruang kelas, ruang workshop/kreatifitas, laboratorium komputer (Multimedia), laboratorium komputer (KKPI), laboratorium komputer (Teknik Komputer \& Jaringan), ruang multimedia umum dan berbagai kegiatan ekstrakulikuler Pramuka, Paskibra, tari saman, marawis, bahasa mandarin, dan olahraga (bola voli,bola basket, karate, tenis meja). SMK Islamic Village Karawaci Kabupaten Tangerang megutamakan sistem pembelajaran praktek, kualitas 
pengajar yang berpengalaman dan profesional dibidangnya, selain itu memiliki banyak prestasi dan telah memenangkan berbagai perlombaan dari bidang akademik maupun diluar akademik.

\section{Storyboard}

Stroryboard adalah rancangan sebuah sketch gambar yang dilengkapi dengan petunjuk atau catatan dalam pengambilan gambar untuk kebutuhan shooting. Selama proses pra produksi, perencanaan yang berhubungan dengan visualisasi yang kemudian akan dibuat membutuhkan Storyboard sebagai media bantuannya.

Tabel 1. Storyboard

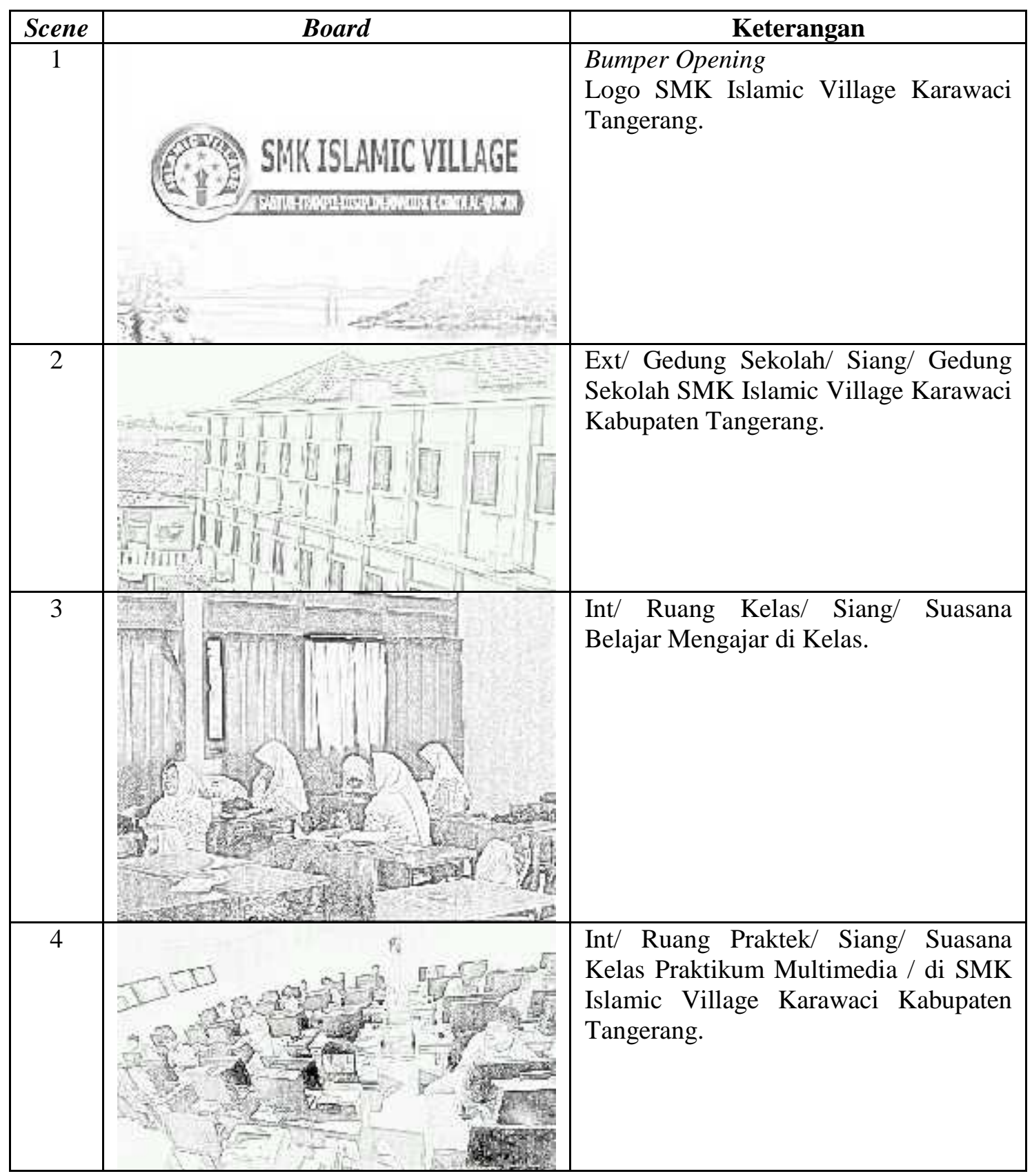




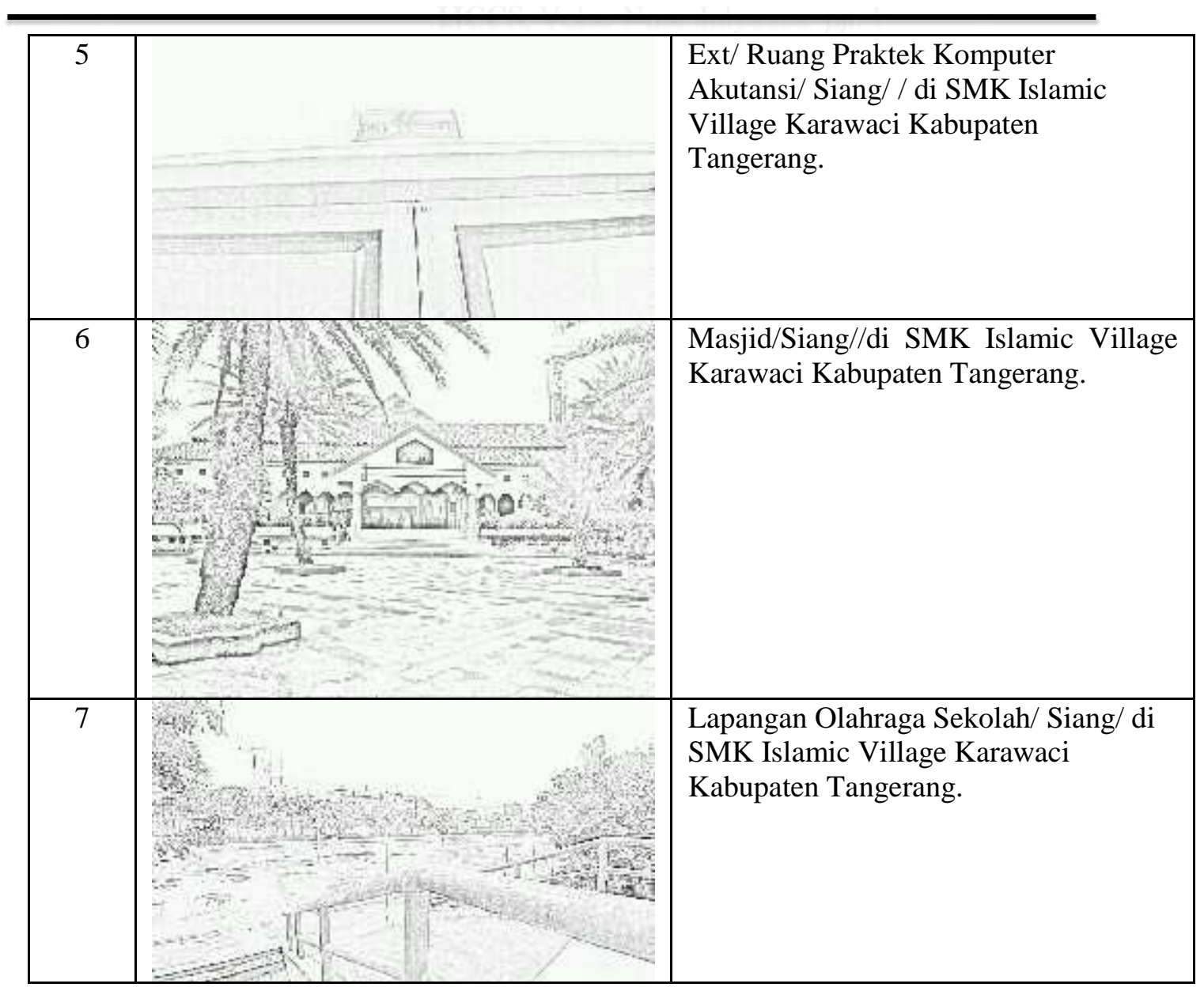

\section{Production}

Production adalah tahap dimana proses shooting video atau pengambilan gambar dengan bekerjasamanya antara pemain dan crew produksi untuk pewujudan rumusan dari tahap preproduction dalam bentuk skenario, naskah, dan storyboard yang telah dibuat. Pada tahan production semua unsur teknis dan kreatif seperti naskah, actor, sinematografi dan suara bergabung dibawah pengawasan kreatif sutradara. Dalam menjalankan proses production shooting video atau pengambilan gambar ada beberapa hal yang harus dipersiapkan dengan baik, diantaranya : desain produksi termasuk storyboard yang bisa menjadi panduan baik tentang hal-hal yang harus dikerjakan selama shooting, kesiapan kru dalam menjalankan perannya masing-masing dan kesiapan perlengkapan yang juga merupakan tanggung jawab masing - masing kru.

\section{Strategi Multimedia}

Geografi : $\quad$ - Kota Tangerang, Kabupaten Tangerang dan Provinsi Banten

Demografi : $\quad$ - Jenis Kelamin : Pria \& Wanita

- Usia $\quad: 15 \mathrm{~s} / \mathrm{d} 18$ tahun

- Kelas Ekonomi : Menengah

- Sasaran : 1. Calon Siswa/i baru

2. Siswa/i Transfer

3. Relasi

4. Masyarakat

Psikografi : Calon Siswa/i, Siswa/i transfer, relasi dan masyarakat yang ingin mengetahui lebih jelas dan bergabung di SMK Islamic Village Karawaci Tangerang. 


\section{Postproduction}

Tahap postproduction adalah proses finishing atau proses akhir dari sebuah karya sampai menjadi sebuah video yang utuh dan mampu menyampaikan isi atau pesan kepada audience. Dalam proses postproduction semua gambar yang didapat pada proses production dikumpulkan di edit oleh seorang editor. Kegitan pemutaran dan distribusi juga masuk di dalam proses postproduction.

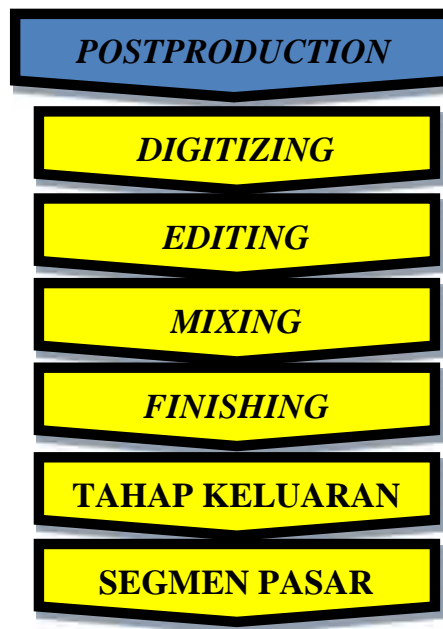

Gambar 6. Tahap Postproduction

\section{Setting Alat}

Dalam pembuatan video profile menggunakan alat Camera Canon 650, Lensa Fix, Tripod, dan Slider. Dalam pembuatan video audio visual ini banyak digunakan di lokasi dalam dan luar sekolah.

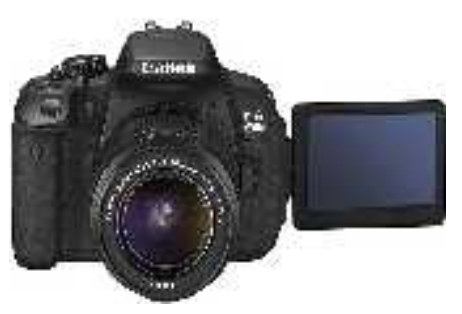

Gambar 7. DSLR Canon 650D

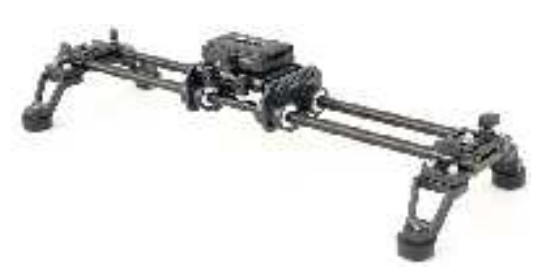

Gambar 9. Slider

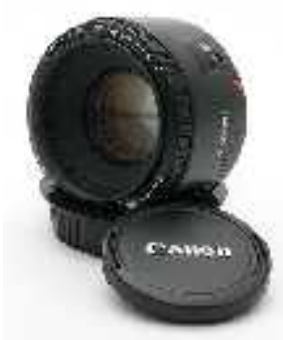

Gambar 8. Lensa fix

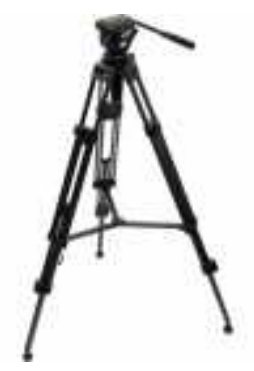

Gambar 10. Tripod

\section{Implementasi Projek}

Perancangan media video profile SMK Islamic Village Karawaci Kabupaten Tangerang ini meliputi sejarah, visi dan misi, mutu, kualitas, prestasi, dan fasilitas yang tersedia. Tabel dibawah ini memaparkan tentang tampilan isi video yang dihasilkan melalui proses perancangan konsep produksi media. 
Tabel 2. Tampilan Video Profile SMK Islamic Village Karawaci Kabupaten Tangerang

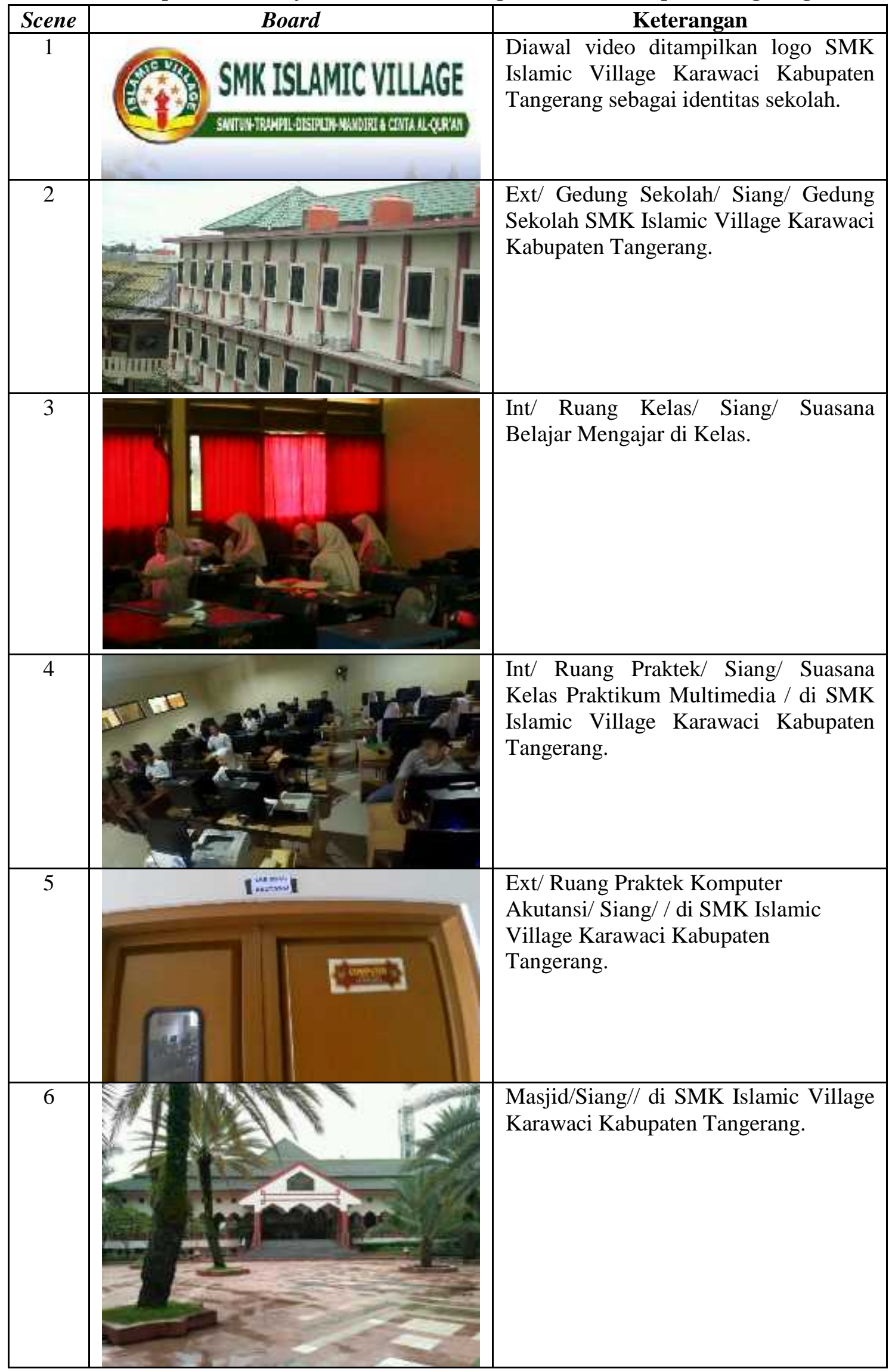




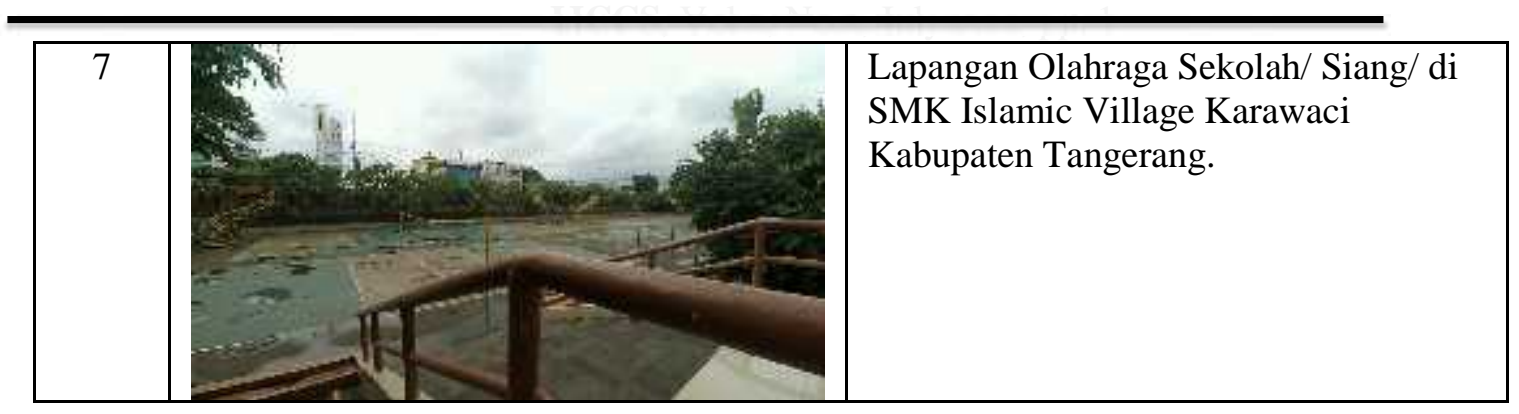

\section{KESIMPULAN}

Agar dapat merancang video profile yang baik harus memenuhi keseluruhan infomasi dari sekolah yang terkait. SMK Islamic Village Karawaci Kabupaten Tangerang membutuhkan media video profile untuk mempermudah pihak sekolah dalam mempromosikan dan menginformasikan ruang lingkup sekolah yang meliputi profil sekolah, sejarah sekolah, akreditasi sekolah, keunggulan sekolah, prestasi sekolah, fasilitas yang dimiliki sekolah, serta visi dan misi sekolah dalam dunia pendidikan dan lain-lain yang dapat memenuhi kebutuhan masyarakat serta menarik kepeminatan calon siswa/i baru untuk bersekolah di SMK Islamic Village Karawaci Kabupaten Tangerang. Perancangan video profile ini dilengkapi dengan narasi yang jelas, singkat, mudah dipahami, disertai effect visual dan visualisasi yang menarik, backsound yang sesuai dan dubbing yang informatif dan jelas, agar informasi yang ingin disampaikan dapat tersampaikan dengan baik kepada sasaran. Melalui perancangan video profile ini, dapat memberikan promosi dan informasi yang efektif serta efisien bagi sekolah, sehingga hasil akhir yang dicapai dari penelitian ini yaitu terciptanya sebuah rancangan media informasi dan promosi berbentuk video profile yang efektif dan sesuai dengan kebutuhan serta mampu meningkatkan target pemasaran yaitu meningkatnya penerimaan siswa/i baru di SMK Islamic Village Karawaci Kabupaten Tangerang sebesar $15 \%$ pada tahun berikutnya.

\section{DAFTAR PUSTAKA}

[1] Ahmad Kausar, Yusuf Fazri Sutiawan, Vidila Rosalina. 2015. Perancangan Video Company Profile Kota Serang Dengan Teknik Editing Menggunakan Adobe Premiere PRO CS 5. Journal PROSISKO ISSN : 2406-7733 Vol. 2 No. 1. Universitas Serang Raya Kota Serang Banten.

[2] Astuti, Indri Tri . 2014. Pembuatan Video Profil Sekolah Dasar Negeri 1 Tugu Jumantono Kabupaten Karanganyar. Jurnal Speed ISSN : 19799330 Vol. 6 No. 1 (Print) - 2088-0154 (Online).

[3] Bentelu, Alan Stevenres, Steven Sentinuwo dan Oktavian Lantang. 2016. Animasi 3 Dimensi Pencegah Cyber Crime (Studi Kasus : Kota Ambon). E-Journal Teknik Informatika Vol. 8, No. 1. Manado : Universitas Sam Ratulangi.

[4] Budiman, Muhammad Adri dan Deddy Irfan. Perancangan Media Presentasi Company Profile Universitas Negeri Padang Berbasis Multimedia Interaktif. Jurnal Voteknika ISSN: 2302-3295 Vol. 4, No. 2. Fakultas Teknik Universitas Negeri Padang.

[5] Desrianti, Dewi Immaniar, Sudaryono dan Dwi Ayu Ningrum. 2014. Enriching Media Merchandise Sarana Penunjang Promosi Studi Kasus Pada Book- Store. Journal CCIT Vol. 2 No. 3. Tangerang : Perguruan Tinggi Raharja.

[6] Firdaus, Septiana, Dhami Johar Damiri, Dewi Tresnawati, 2012, Perancangan Aplikasi Multimedia Interaktif Company Profile Generic (Studi Kasus CV. GANETIC), Jurnal Algoritma ISSN : 2302-7339 Vol. 01 No. 09, hal 1-10, Sekolah Tinggi Teknologi Garut, Jawa Barat.

[7] Hutahaen, Jeperson. 2015. Konsep Sistem Informasi. Yogyakarta : Deepublish. 
[8] Mahmudi,Muh Ali. Pembuatan Video Profile Sekolah Dasar Negeri Tlogo CV Bootsector. Journal Speed ISSN : 1979-9330 Vol.7 No. 3 (Print) 2088-0154 (Online)

[9] Maimunah, Lusyani Sunarya, Nina Larasati. 2012. Media Company Profile sebagai Sarana Promosi dan Informasi. Journal CCIT Vol.5 No.3. Tangerang : PerguruanTinggi Raharja.

[10] Madcoms. 2012. Kupas Tuntas Adobe Photoshop CS6. Yogyakarta : ANDI.

[11] Saftanto, Soma Dwi. 2013. Pembuatan Video Company Profile Pada Sekolah Menengah Atas Muhammadiyah 1 Karanganyar. Jurnal Seruni ISSN: $2302-1136$ Vol 2 No 1, hal 242-245, Nasional Informatika dan Komputer FTI UNSA.

[12] Sutrisno, Aziz Ahmadi, 2015, Pembuatan Video Profil Sekolah Dasar Negeri Menadi Kabupaten Pacitan Berbasis Multimedia. Speed Journal - Sentra Penelitian Engineering dan Edukasi - Vol. 12 No 1 - 2015, ISSN : 1979-9330 (Print) - 2088-0154 (Online).

[13] Sunarya, Lusyani. Rindang Kusumaninggar dan Adrian Syahputra. 2017. Perancangan Media Promosi Video Profile Pada SMA Negeri 15 Kota Tangerang. Jurnal Eksplora Informatika. Vol 5 No 2, hal 106-107. STMIK Raharja Tangerang.

[14] Waloeya, Yohan Jari. 2012. Seri Belajar Kilat Adobe After Effect CS5. Yogyakarta: ANDI. [12] Waloeya, Yohan Jari. 2012. Seri Belajar Kilat Adobe After Effect CS5. Yogyakarta : ANDI. 